\title{
Assessment of quality in screening colonoscopy for colorectal cancer
}

This article was published in the following Dove Press journal:

Clinical and Experimental Gastroenterology

9 December 201 I

Number of times this article has been viewed

\section{Ana Rita Gonçalves \\ Carlos Ferreira \\ António Marques \\ Luís Carrilho Ribeiro \\ José Velosa}

Department of Gastroenterology and Hepatology, Hospital Santa Maria-CHLN, Lisboa I068,

Portugal
Correspondence: Ana Rita Gonçalves Department of Gastroenterology and Hepatology, Hospital Santa Maria-CHLN, Lisboa 1068, Portugal

Tel +351963892223

Email ritmica20@hotmail.com
Introduction: The effectiveness of screening colonoscopy in decreasing the incidence of colorectal cancer (CRC) is largely dependent on the detection of polyps and the quality of the procedure. Several key quality measures have been proposed to improve the effectiveness of screening colonoscopies.

Aim: To evaluate quality indicators of screening colonoscopy in a tertiary hospital.

Methods: All CRC screening colonoscopies performed between 2005 and 2009 in a single tertiary center were reviewed for internationally accepted quality measures.

Results: Of the 1545 individuals who underwent first-time screening colonoscopy 38\% were male and $62 \%$ were female. The mean age of the patients was 60.4 years and the mean difference in ages was \pm 10.3 years. Cecal intubation rate was $91 \%$ (1336), however ileocecal valve photo documentation was performed in only $81 \%$ (1248) colonoscopies. The quality of bowel preparation was classified as: good 76\% (1171), reasonable 11\% (174), and poor 13\% (200). Polyp detection rate (PDR) was 33\% (503). The prevalence of polyps $\geq 1 \mathrm{~cm}$ in size was $5 \%$ (82). PDR was significantly higher in men than in women (44\% [260] vs 25\% [243], $P=0.0001)$. Other factors significantly influencing PDR were quality of bowel preparation (odds ratio [OR]: 1.28, 95\% confidence interval [CI]: 0.9-1.6) and age over 50 (OR: 1.9, 95\% CI: 1.3-2.9). Left colonic polyps were associated with a risk ratio of 2.3 (95\% CI: 1.8-2.9) of lesions in the other colonic segments compared to no polyps in the left colon. None of the colonoscopists reported withdrawal time. Conclusion: Cecal intubation rate and quality of bowel preparation were suboptimal. The polyp detection rate compares favorably to accepted standards and its main determinants are male sex, age $>50$ years, quality of bowel preparation, and the presence of left colonic polyps.

Keywords: colorectal cancer, screening colonoscopy, quality indicators

\section{Introduction}

The incidence of colorectal cancer $(\mathrm{CRC})$ is rising in Europe and it is estimated that every year more than 400,000 patients are newly diagnosed with CRC. ${ }^{1}$ Most cancers grow relatively slowly over 10-15 years and the development of CRC is attributed to the adenoma-carcinoma sequence. ${ }^{2}$ This window period allows for screening and prevention of CRC by endoscopic removal of polyps. Many experts and scientific societies advocate colonoscopy as the method of choice for screening and prevention of CRC. ${ }^{3-5}$ Although there is good evidence for the positive impact in the reduction of $\mathrm{CRC}$ it is also recognized that its effectiveness is dependent on the quality of the procedure ${ }^{6-8}$ which, unfortunately, is very variable in the clinical practice. A number of key quality indicators have been recommended. In 2002, quality indicators for colonoscopy were published by the American Society for Gastrointestinal 
Endoscopy/American College of Gastroenterology (ASGE/ ACG) and further adjusted by Rex et al. ${ }^{8,9}$ The key indicators proposed were: preprocedure (appropriate indication and use of surveillance intervals, informed consent); intraprocedure (documentation of quality of bowel preparation, cecal intubation rates with photodocumentation of cecal landmarks, adenoma detection rate, withdrawal time $>6$ minutes, adequate resection of polyps); postprocedure (measurement of incidence of perforation, post-polypectomy bleeding and nonoperative management of post-polypectomy bleeding). Lieberman was the lead author of the report of the Quality Assurance Task Group of the National Colorectal Cancer Roundtable that developed a reporting and data system for colonoscopy to assist endoscopists in monitoring quality indicators in their practice. ${ }^{10}$ European guidelines for quality assurance in CRC screening and diagnosis have recently been published. ${ }^{11}$ Most CRC screening programs now incorporate routine assessment of the quality of examinations as a way to improve screening colonoscopy clinical outcomes. The quality of colonoscopies cannot be measured or improved if reports do not include key quality indicators. The objectives of our study were (1) to determine if screening colonoscopy reports in our center included key quality indicators and (2) to measure the actual performance of our examinations when compared to accepted standards.

\section{Methods}

We retrospectively analyzed all colonoscopy reports of the examinations performed between 2005 and 2009 in our Gastroenterology Department which we coded in our database as screening colonoscopies for CRC. Only total colonoscopies (as intended) where included. All of the examinations were performed by board-certified specialists or fellows in training. A total of 1545 first-time screening colonoscopies were eligible for data analysis. Procedurerelated quality indicators considered for analysis were: cecal intubation rate and photodocumentation of cecal landmarks (ileocecal valve, appendiceal orifice, or terminal ileum), quality of bowel preparation, and polyp detection rate. The quality of bowel preparation was subjectively classified at the time of the examination by each endoscopist as good, fair, or poor, so we adopted these three grades of bowel preparation. The polyp detection rate instead of adenoma detection rate was considered since we did not have pathology data for all of the examinations. Accordingly, polyps $\geq 10 \mathrm{~mm}$ were considered surrogate markers for advanced neoplasia. ${ }^{12}$ We correlated polyp detection rate with sex and age (dichotomized as $<50$ vs $\geq 50$ years old), quality of bowel preparation, and use of sedation. Statistical analysis was performed using Microsoft Excel (Microsoft Corp, Redmond, WA) and SAS software (v 9.1; SAS Institute, Inc, Cary, NC). Multivariate analysis was used to determine factors influencing the polyp detection rate. A value of $P<0.05$ was considered significant.

\section{Results}

The patient demographics are shown in Table 1. A total of 1545 examinations corresponding to 1545 patients were made. The distribution according to gender was $62 \%$ female and $38 \%$ male. The mean age of the patients was 60.4 years and the mean difference in ages was \pm 10.3 years. Seventy percent of the patients were between 50 and 70 years old. Cecal intubation was successful in 91\% (1336) of the colonoscopies although documentation of either three of the landmarks considered was present in only $81 \%$ (1248). Incomplete colonoscopies accounted for 14\% (209) of the examinations. The motives for incomplete colonoscopy were patient intolerance $40 \%$ (84), inadequate bowel preparation $35 \%$ (73), technical difficulties 18\% (37), and obstructive lesion $0.5 \%$ (1). A second screening colonoscopy within the same year was performed on only $30 \%$ (62) of patients with incomplete colonoscopies, of which $40 \%$ had polyps.

The quality of bowel preparation was classified as: good $76 \%$ (1171), fair 11\% (174), and poor 13\% (200). There was no significant gender difference in the quality of bowel preparation. Sixty-seven percent (1046) of the colonoscopies were performed without sedation, 25\% (392) under conscious sedation, and 7\% (107) under deep sedation. Although there were more incomplete examinations due to intolerance in patients without sedation than in patients with

Table I Patient characteristics

\begin{tabular}{ll}
\hline Gender & $\mathbf{N}(\%)$ \\
Male & $587(38)$ \\
Female & $958(62)$ \\
Age (years) & Median \\
Patients & $60.4( \pm 10.3)$ \\
Male & $64.9( \pm 9.8)$ \\
Female & $60.1( \pm 10.5)$ \\
Age, stratified & $\mathbf{N}(\%)$ \\
$20-29$ & $14(0.9)$ \\
$30-40$ & $34(2.2)$ \\
$40-50$ & $119(7.7)$ \\
$50-60$ & $548(35.5)$ \\
$60-70$ & $552(35.7)$ \\
$70-80$ & $225(14.6)$ \\
$80-90$ & $40(2.6)$ \\
$>90$ & $3(0.2)$ \\
\hline
\end{tabular}


conscious sedation (6\% [64] vs 5\% [19]), the difference was not significant $(P=0.31)$.

The overall polyp detection rate (PDR) was 33\% (503). The prevalence of polyps $\geq 10 \mathrm{~mm}$ in size, a surrogate marker for advanced neoplasia, was 5\% (82). The polyp distribution was as follows: left colon $74 \%$ (370), right colon $31 \%$ (153), and transverse colon $17 \%$ (86) patients. In $26 \%$ (98) of the patients with left colonic polyps, synchronous polyps in the transverse or right colon were also detected. The presence of left colonic polyps was associated with a risk ratio of 2.3 (95\% confidence interval [CI]: 1.8-2.9) for lesions in other colonic segments compared to no polyps in the left colon. Male gender was a major risk factor for the presence of polyps. PDR was significantly higher in men than in women (44\% [260] vs $25 \%$ [243], $P=0.0001)$ with an odds ratio [OR] of 2.3 (95\% CI: 1.8-2.9). Men also had a significantly higher prevalence of polyps $\geq 1 \mathrm{~cm}$ (9\% [50] vs $3 \%$ [32], $P=0.002)$ and multiple polyps (22\% [126] vs $11 \%$ [105], $P=0.0001$ ), compared to women. Polyps were more frequently detected in patients aged $\geq 50$ years than in those $<50$ years ( $34 \%$ vs $20 \%, P=0.0004)$. PDR was higher in patients with good bowel preparation compared to reasonable or poor bowel preparation ( $34 \%$ vs $28 \%$, OR: 1.28 , 95\% CI: $0.9-1.6)$. Polyps where detected in $34 \%$ of colonoscopies with deep/conscious sedation compared to $32 \%$ in colonoscopies without sedation but this difference was not significant $(P=0.38)$. Colorectal cancer was found in $0.3 \%$ (five) patients (three men and two women, mean age 68 years). Of these, two (40\%) had at least one synchronous polyp, both in the left colon.

\section{Discussion}

Colonoscopy has become accepted as a powerful screening tool for CRC prevention and early diagnosis since 2000 , when two landmark articles ${ }^{13,14}$ were published describing results of screening colonoscopy and its feasibility and ability to provide definitive insights into the types and locations of important advanced neoplastic lesions that would be missed with sigmoidoscopy. Although the efficacy of colonoscopy in reducing CRC incidence and mortality is well established, there are some major pitfalls. Firstly, the positive impact of colonoscopy is largely operator-dependent, ${ }^{6,8,18}$ highlighting the importance of the quality of the procedure. Secondly, colonoscopy seems to provide more protection against distal rather than proximal colon cancer, as pointed out by Canadian case-control and cohort studies. ${ }^{15-18}$ The relative ineffectiveness of screening colonoscopy in the prevention of proximal colon cancer might be explained by certain biological features of neoplasms at this level ${ }^{19}$ but also by potentially correctable factors related to the quality of the examination. The importance of defining and establishing uniform quality benchmarks for screening colonoscopy as a way to overcome these pitfalls and assure the positive impact of this examination has been recognized. In our study we analyzed some of the key quality indicators for screening colonoscopies and compared them to the proposed standards by ASGE/ACG ${ }^{8,9}$ as a first step to improve our practice.

Completion rates have been proposed as a quality metric because it is reasonable to assume that the effectiveness of colonoscopy is limited if the entire colon is not routinely examined. Cecal intubation is defined as passing the tip of the endoscope beyond the ileocecal valve lip. Photodocumentation is recommended and important from a medical-legal perspective. Our observed cecal intubation rate (91\%) is suboptimal compared to the ASGE benchmark of $95 \%$. Variations in cecal intubation rates are due to physician variables (skill including dexterity, training level), patient variables (age, gender, body mass index, past surgeries, tortuousity of the colon, pain threshold, and response to anesthesia), and the adequacy of bowel preparation..$^{20-22}$ In our study we found that there were two main factors which contributed to incomplete colonoscopies. Firstly, patient intolerance in $40 \%$ (84) was the major motive for an incomplete examination. Because of logistical restrictions the majority of the colonoscopies where performed without sedation (67\%) and this may have contributed to a high incidence of patient intolerance. Secondly, there was a higher incidence than desirable of patients with poor bowel preparation (13\%).

A major limitation of our study was the subjective assessment of bowel preparation. The perception of good, fair, or poor between our endoscopists is highly variable and only a few report the quality of preparation if it is poor. We considered such reports to be indicative of good bowel preparation. The ASGE guidelines recommend that documentation of bowel preparation should be done in every examination. Although there is no standardized system for this, an adequate preparation is one that allows the clear detection of lesions $>5 \mathrm{~mm}$. The percentage of examinations with poor bowel preparation should be less than $10 \%,{ }^{9}$ a benchmark which we did not achieve. This should warn us to give special attention to our implemented bowel preparation protocol. Recent studies have shown that split dose polyethylene glycol-electrolyte (PEG) is more effective than conventional bowel preparation $\mathrm{s}^{23}$ and that adherence to dietary instructions has a significant impact on the quality of bowel preparation. ${ }^{24}$ 
The adenoma detection rate (ADR) was developed as a quality indicator in 2002. ${ }^{9}$ It has been validated as a powerful predictor of CRC risk after screening colonoscopy. ${ }^{25} \mathrm{~A}$ recent study by Baxter (2009) found that patients colonoscoped by doctors with polypectomy rates of $25 \%-29 \%$ and $\geq 30 \%$ had $52 \%$ and $39 \%$ lower incidence rates, respectively, of subsequent proximal colon cancers compared with patients colonoscoped by doctors with polypectomy rates $\leq 10 \%{ }^{26}$ The ASGE/ACG recommendations propose that adenomas should be detected in more than $25 \%$ of the asymptomatic male individuals ( $>50$ years) and in more than $15 \%$ of the asymptomatic female individuals ( $>50$ years) at first colonoscopy because prevalence rates of adenomas in colonoscopy screening studies have been consistently over $25 \%$ in men and $15 \%$ in women $>50$ years old. ${ }^{14}$ The Bowel Cancer Screening Program (BCSP) in the UK requires an $\mathrm{ADR}$ of $35 \% .{ }^{27} \mathrm{ADR}$ is cumbersome to calculate as it needs to be correlated with pathology data not readily available at the time of the procedure. There have been recent studies that show that PDR is a useful quality measure with a good correlation with the ADR. In a study by Williams et al, the PDRs by endoscopists correlated well with their ADRs $\left.\left(r_{s}\right)=0.86, P<0.001\right)$. To attain the established benchmark ADRs for men (25\%) and women (15\%), endoscopists needed PDRs of $40 \%$ and $30 \%$, respectively. ${ }^{28}$ In our study, we used the PDR as a surrogate marker of the ADR and we were able to fulfill the requirements of this recently defined benchmark (44\% for men and 25\% for women). Despite our suboptimal cecal intubation rate and quality of bowel preparation, does our good PDR mean that we are doing these fairly well? It is known that adenoma detection is dependent on many different variables. Firstly, the baseline demographic features of the population screened, such as male sex and age above 50 years and to a lesser extent family history of colorectal neoplasia, influence the ADR. Secondly, factors related to the technique of the examination - such as the speciality of the endoscopist (gastroenterologist vs non-gastroenterologist), ${ }^{29,30}$ quality of bowel preparation, and withdrawal time - also influence the ADR. Withdrawal times are directly linked to ADRs, because a more careful inspection leads to a greater yield. Studies have demonstrated increased detection of significant neoplastic lesions in colonoscopic examinations where the withdrawal time is 6 minutes or more. ${ }^{31}$ In our study, none of the endoscopists reported withdrawal times, which can be seen as a major limitation. However, nowadays it is recognized that endoscopists who meet the ADR benchmark are likely to have satisfactory withdrawal technique. Our results regarding gender, age, and quality of bowel preparation as influencing factors for PDR are in accordance with the published literature. We did not find a significant difference in PDR between examinations with sedation or without sedation.

Our study has several limitations, as already pointed out. Being a retrospective study, there was missing data regarding some of the most important quality indicators, such as withdrawal time, standardized description of the quality of bowel preparation, and the adenoma detection rate. The only clear quality indicator we documented was the cecal intubation rate. With this data, we acknowledge that the assessment of the quality of screening colonoscopies in our center is limited and it cannot be extrapolated nationwide. Nevertheless, it is the first study in our country where to date a national colonoscopy screening program for colorectal cancer has not been implemented. Our study provides crucial input for improving the quality of our examinations and highlights the need to implement the use and the systematic report of these quality benchmarks before establishing a screening program.

\section{Conclusion}

Although colonoscopy screening has been documented to confer a high degree of protection against CRC in clinical trials, its population-based field efficacy is dependent on a high-quality procedure. Several quality indicators have been validated and incorporated in screening programs worldwide. In our center some of these quality indicators are still suboptimal. In the future we should aim to improve the quality of our examinations. Future research should be directed at determining the best way to use these quality indicators for colonoscopy in a manner that results in improved patient care and outcome.

\section{Acknowledgments}

AR Gonçalves and C Ferreira contributed equally to this work; AR Gonçalves and C Ferreira collected data, performed research, and wrote the paper; A Marques, LC Ribeiro, and J Velosa revised the paper. There are no supportive foundations to acknowledge.

\section{Disclosure}

The authors report no conflicts of interest in this work.

\section{References}

1. Ferlay J, Parkin DM, Steliarova-Foucher E. Estimates of cancer incidence and mortality in Europe in 2008. Eur J Cancer. 2010;46(4):765-781.

2. Kim EC, Lance P. Colorectal polyps and their relationship to cancer. Gastroenterol Clin North Am. 1997;26(1):1-17. 
3. Rex DK, Johnson DA, Anderson JC, Schoenfeld PS, Burke CA, Inadomi JM; American College of Gastroenterology. American College of Gastroenterology guidelines for colorectal cancer screening 2009 [corrected]. Am J Gastroenterol. 2009;104(3):739-750.

4. Levin B, Lieberman DA, McFarland B, et al; American Cancer Society Colorectal Cancer Advisory Group; US Multi-Society Task Force; American College of Radiology Colon Cancer Committee. Screening and surveillance for the early detection of colorectal cancer and adenomatous polyps, 2008: a joint guideline from the American Cancer Society, the US Multi-Society Task Force on Colorectal Cancer, and the American College of Radiology. Gastroenterology. 2008; 134(5):1570-1595.

5. Klabunde CN, Lanier D, Nadel MR, McLeod C, Yuan G, Vernon SW. Colorectal cancer screening by primary care physicians: recommendations and practices, 2006-2007. Am J Prev Med. 2009;37(1):8-16.

6. Chen SC, Rex DK. Endoscopist can be more powerful than age and male gender in predicting adenoma detection at colonoscopy. Am J Gastroenterol. 2007;102(4):856-861.

7. Barclay RL, Vicari JJ, Doughty AS, Johanson JF, Greenlaw RL. Colonoscopic withdrawal times and adenoma detection during screening colonoscopy. N Engl J Med. 2006;355(24):2533-2541.

8. Rex DK, Petrini JL, Baron TH, et al; ASGE/ACG Taskforce on Quality in Endoscopy. Quality indicators for colonoscopy. Am J Gastroenterol. 2006;101(4):873-885.

9. Rex DK, Bond JH, Winawer S, et al; US Multi-Society Task Force on Colorectal Cancer. Quality in the technical performance of colonoscopy and the continuous quality improvement process for colonoscopy: recommendations of the US multi-society task force on colorectal cancer. Am J Gastroenterol. 2002;97(6):1296-1308.

10. Lieberman D, Nadel M, Smith RA, et al. Standardized colonoscopy reporting and data system: report of the quality assurance task group of the national colorectal cancer roundtable. Gastrointest Endosc. 2007; 65(6):757-766.

11. Valori R, Rey J-F, Atkin W, et al. Guidelines for quality assurance of endoscopy in colorectal cancer screening (and diagnosis). In: Patnick J, Segnan N, Von Karsa I, editors. European Guidelines for Quality Assurance in Colorectal Cancer Screening. Lyon, France: IARC. In press.

12. Lieberman D, Moravec M, Holub J, Michaels L, Eisen G. Polyp size and advanced histology in patients undergoing colonoscopy screening: implications for CT colonography. Gastroenterology. 2008;135(4): 1100-1105.

13. Imperiale TF, Wagner DR, Lin CY, Larkin GN, Rogge JD, Ransohoff DF. Risk of advanced proximal neoplasms in asymptomatic adults according to the distal colorectal findings. N Engl J Med. 2000;343(3):169-174.

14. Lieberman DA, Weiss DG, Bond JH, Ahnen DJ, Garewal H, Chejfec G Use of colonoscopy to screen asymptomatic adults for colorectal cancer. Veterans Affairs Cooperative Study Group 380. N Engl J Med. 2000; 343(3): 162-168

15. Lakoff J, Paszat LF, Saskin R, Rabeneck L. Risk of developing proximal versus distal colorectal cancer after a negative colonoscopy: a populationbased study. Clin Gastroenterol Hepatol. 2008;6(10):1117-1122.
16. Singh $H$, Nugent $Z$, Mahmud SM, Demers AA, Bernstein CN. Predictors of colorectal cancer after negative colonoscopy: a population-based study. Am J Gastroenterol. 2010;105(3):663-673.

17. Baxter NN, Goldwasser MA, Paszat LF, Saskin R, Urbach DR, Rabeneck L. Association of colonoscopy and death from colorectal cancer. Ann Intern Med. 2009;150(1):1-8.

18. Singh H, Nugent Z, Demers AA, Kliewer EV, Mahmud SM, Bernstein $\mathrm{CN}$. The reduction in colorectal cancer mortality after colonoscopy varies by site of the cancer. Gastroenterology. 2010;139(4): $1128-1137$

19. Farrar WD, Sawhney MS, Nelson DB, Lederle FA, Bond JH. Colorectal cancers found after a complete colonoscopy. Clin Gastroenterol Hepatol. 2006;4(10):1259-1264.

20. Aslinia F, Uradomo L, Steele A, Greenwald BD, Raufman JP. Quality assessment of colonoscopic cecal intubation: an analysis of 6 years of continuous practice at a university hospital. Am J Gastroenterol. 2006; 101(4):721-731.

21. Barclay RL, Vicari JJ, Doughty AS, Johanson JF, Greenlaw RL. Colonoscopic withdrawal times and adenoma detection during screening colonoscopy. N Engl J Med. 2006;355(24):2533-2541.

22. Cotton PB, Connor P, McGee D, et al. Colonoscopy: practice variation among 69 hospital-based endoscopists. Gastrointest Endosc. 2003; 57(3):352-357.

23. Aoun E, Abdul-Baki H, Azar C, et al. A randomized single-blind trial of split-dose PEG-electrolyte solution without dietary restriction compared with whole dose PEG-electrolyte solution with dietary restriction for colonoscopy preparation. Gastrointest Endosc. 2005;62(2):213-218.

24. Modi C, Depasquale JR, Digiacomo WS, et al. Impact of patient education on quality of bowel preparation in outpatient colonoscopies. Qual Prim Care. 2009;17(6):397-404.

25. Kaminski MF, Regula J, Kraszewska E, et al. Quality indicators for colonoscopy and the risk of interval cancer. $N$ Engl J Med. 2010; 362(19): 1795-1803.

26. Baxter NN, Sutradhar R, Forbes SS, Paszat LF, Saskin R, Rabeneck L. Analysis of administrative data finds endoscopist quality measures associated with postcolonoscopy colorectal cancer. Gastroenterology. 2011;140(1):65-72.

27. NHS Bowel Cancer Screening Programme. Quality assurance guidelines for colonoscopy. NHA BCSP Publication No 6; March 2010.

28. Williams JE, Le TD, Faigel DO. Polypectomy rate as a quality measure for colonoscopy. Gastrointest Endosc. 2011;73(3):498-506.

29. Bressler B, Paszat LF, Vinden C, Li C, He J, Rabeneck L. Colonoscopic miss rates for right-sided colon cancer: a population-based analysis Gastroenterology. 2004;127(2):452-456.

30. Bressler B, Paszat L, Rothwell D, et al. Predictors of missed colorectal cancer during colonoscopy: a population-based analysis [abstract] Gastrointest Endosc. 2005;61:AB24.

31. Barclay R, Vicari JJ, Johanson JF, et al. Variation in adenoma detection rates and colonoscopic withdrawal times during screening colonoscopy [abstract]. Gastrointest Endosc. 2005;61:AB107.
Clinical and Experimental Gastroenterology

\section{Publish your work in this journal}

Clinical and Experimental Gastroenterology is an international, peerreviewed, open access journal, publishing all aspects of gastroenterology in the clinic and laboratory, including: Pathology, pathophysiology of gastrointestinal disease; Investigation and treatment of gastointestinal disease; Pharmacology of drugs used in the alimentary tract;

\section{Dovepress}

Immunology/genetics/genomics related to gastrointestinal disease. This journal is indexed on CAS. The manuscript management system is completely online and includes a very quick and fair peer-review system. Visit http://www.dovepress.com/testimonials.php to read real quotes from published authors. 